\title{
How can we further improve the LDL-cholesterol target level achievement rate based on the Hungarian MULTI GAP 2011 study results and considering the new European dyslipidemia guidelines?
}

\author{
Laszlo Mark', György Paragh², Istvan Karadi ${ }^{3}$ Istvan Reiber ${ }^{4}$, Gyula Pados ${ }^{5}$, Zoltan Kiss ${ }^{6}$
}

\author{
$1^{\text {nd }}$ Department of Medicine - Cardiology, Pandy Kalman Bekes County Hospital, \\ Gyula, Hungary \\ $21^{\text {st }}$ Department of Medicine, Medical and Health Science Centre, University \\ of Debrecen, Hungary \\ 33rd Department of Medicine, Semmelweis University, Budapest, Hungary \\ $44^{\text {th }}$ Department of Medicine, St. George Fejer County Hospital, Szekesfehervar, \\ Hungary \\ 5St. Imre Hospital, Independent Department of Lipidology, Budapest, Hungary \\ ${ }^{6} \mathrm{MSD}$ Hungary Kft, Budapest, Hungary
}

Submitted: 29 February 2012

Accepted: 15 May 2012

Arch Med Sci 2012; 8, 4: 608-613

DOI: 10.5114 /aoms.2012.30283

Copyright (c) 2012 Termedia \& Banach

\begin{abstract}
Introduction: Despite the continuous improvement of the quality of lipid lowering therapy the achievement of target values is still not satisfactory, mainly in the very high cardiovascular risk category patients, where the goal of low density lipoprotein cholesterol (LDL-C) is $1.80 \mathrm{mmol} / \mathrm{l}$.

Material and methods: The trends in lipid lowering treatment of 17420 patients from different studies conducted between 2004 and 2010 were compared to that of 1626 patients of MULTI GAP (MULTI Goal Attainment Problem) 2011 treated by general practitioners (GPs) and specialists.

Results: In MULTI GAP 2011 the mean LDL-C level \pm SD) of patients treated by GPs was found to be $2.87 \pm 1.01 \mathrm{mmol} / \mathrm{l}$, the target value of 2.50 was achieved by $40 \%$ of them, in the specialists' patients the mean LDL-C level proved to be $2.77 \pm 1.10 \mathrm{mmol} / \mathrm{l}$ and the achievement rate was $45 \%$. In the $2.50 \mathrm{mmol} / \mathrm{l}$ achievement rate of GPs' patients a satisfactory improvement was observed in the studied years, but the $1.80 \mathrm{mmol} / \mathrm{LDL}-\mathrm{C}$ goal in 2011 was attained only in $11 \%$ of very high risk cases. There was a linear correlation between the patient compliance estimated by the physicians and the LDL-C achievement rate.

Conclusions: As the number of very high risk category patients has been increased according to the new European dyslipidemia guidelines, growing attention needs to be placed on attainment of the $1.80 \mathrm{mmol} / \mathrm{L}$ LDL-C level. Based on the results of the MULTI GAP studies, improving patients' adherence and the continuous training of physicians are necessary.
\end{abstract}

Key words: prevention, risk factors, hypercholesterolemia, LDL cholesterol.

\section{Introduction}

Lipid-lowering therapy, the basic drugs of which are statins, became cardiovascular prevention's most important element in recent years. A series of studies showed that the administration of statins can reduce cardiovascular events and mortality as well [1-3]. Recently the issue came

\author{
Corresponding author: \\ Laszlo Mark MD, PhD \\ $2^{\text {nd }}$ Department of \\ Internal Medicine - \\ Cardiology \\ Pandy Kalman Bekes \\ County Hospital \\ Semmelweis u. 1 \\ P.O. Box 46 \\ 5701 Gyula, Hungary \\ Phone: +36-209288053 \\ Fax: +36-66526543 \\ E-mail: mark@pandy.hu
}


up that this group of medicines could increase the occurrence of new onset diabetes; however, the benefit of statin application is not comparable to the harm of this possible side effect, especially in patients with known vascular disease [4-6].

The goal of lipid-lowering therapy is always to reduce the frequency of cardiovascular events. However, within this there is a well-defined surrogate endpoint of stopping the progression or causing the regression of atherosclerosis that is considered the cause the clinical events. A series of studies has proved that lowering the LDL-C level by $50 \%$ could result in regression of atherosclerotic plaques [7-9]. All this makes understandable the fact that in the new European dyslipidemia guidelines the number of diseases belonging to the very high risk category has been enlarged [10]. If vascular stenosis is detected, an effort should be made to stop the process and start its regression, aiming to reach the $1.80 \mathrm{mmol} / \mathrm{l}$ target level and exceed the $50 \%$ reduction of LDL-cholesterol level.

Most of the previous studies demonstrated that the attainment rate of the $2.50 \mathrm{mmol} / \mathrm{LDL}-\mathrm{C}$ level is insufficient. How can we reach this target when most of our patients should achieve the $1.80 \mathrm{mmol} / \mathrm{l}$ LDL-C level already? What conclusions can be drawn from the survey conducted since 2004 and the MULTI GAP 2011 results in order to treat our patients more effectively? Although this survey was conducted in Hungary, the comparison made with the earlier international studies showed that the problems are similar in all European countries [11-16]; therefore we believe that the lessons learned from this investigation may be valid for other countries as well.

\section{Material and methods}

The trends in lipid lowering treatment were studied using the data of 17420 patients in total from different surveys (CEL Program 2004 and 2005, KONSZENZUS-CEL Program 2006, REALITY 2004 and 2007 studies, MULTI GAP 2008, 2009 and 2010) performed on high cardiovascular risk patients of GPS and specialists in Hungary $[17,18]$.

In the MULTI-GAP 2011 study we analyzed data and treatment strategies of 1626 patients from 149 randomly selected specialists (73 specialists of internal medicine, 40 cardiologists, 16 diabetologists, 20 neurologists) and 53 GPs (approximately 10 patients per physician were enrolled) using a structured questionnaire in August and September 2011.

The patients gave their consent to participation; the study was conducted in accordance with the Declaration of Helsinki and ICH-GCP (International Conference on Harmonisation - Good Clinical Practice).

The MULTI GAP 2011 patients involved 383 cases of unstable angina, 560 cases of previous myocardial infarction, 283 with known peripheral artery disease (PAD) or vascular operation due to PAD, 481 with stroke and 279 with transitory ischemic attack; 766 patients were diabetic and 1430 had hypertension. The existence and extent of smoking, as well as the sex, age, body mass index and waist circumference were recorded.

The physicians also estimated patients' compliance based on frequency of statin prescription and questioning the patient.

All patients belonged at least to the high cardiovascular risk category according to the $4^{\text {th }}$ Hungarian Cardiovascular Consensus Conference recommendations [19], and they had LDL-C targets at least of $\leq 2.50 \mathrm{mmol} / \mathrm{l}$. Stratifying the patients according the new dyslipidemia guidelines of the ESC/EAS (European Society of Cardiology and European Atherosclerosis Society), $83 \%$ of them belonged to the very high risk category with an LDL-C target value of $1.80 \mathrm{mmol} / \mathrm{l}$ [10].

\section{Statistical analysis}

In the case of categorical variables we used frequencies of valid cases. In the case of continuous variables means and medians are presented. Significance tests were performed by $\chi^{2}$ for categorical, by ANOVA for continuous variables (with Fisher's least significant difference [LSD] test method for multiple comparisons). Asymmetric 2-sided scores were considered. Values of $p$ (two-tailed) $<0.05$ were accepted as significant. All statistical analyses were performed by SPSS.

\section{Results}

In the MULTI GAP 2011 study 1626 patients participated, 683 women and 943 men; their mean age was $66.0 \pm 10$ years, body mass index $29.0 \pm 10 \mathrm{~kg} / \mathrm{m}^{2}$, eGFR $61 \pm 13 \mathrm{ml} / \mathrm{min} / 1.73 \mathrm{~m}^{2}, 28 \%$ of the patients were smokers (among the smokers 28\% smoked 10 or less cigarettes/day, $48 \%$ between 10 and 20 , and $24 \% 20$ or more) (Table I).

The mean LDL-C level ( \pm SD) of the total population was $2.82 \pm 1.0 \mathrm{mmol} / \mathrm{l}$, the attainment rate of $2.50 \mathrm{mmol} / \mathrm{l}$ was $43.3 \%$. The mean LDL-C values of GPs' and specialists' patients were 2.87 $\pm 1.00 \mathrm{mmol} / \mathrm{l}$ and $2.77 \pm 1.10 \mathrm{mmol} / \mathrm{l}$, respectively (Table I). Figure 1 presents changes in LDL-C level between 2004 and 2011; it shows a decrease of almost $1.0 \mathrm{mmol} / \mathrm{l}$ for patients treated by GPs. In Figure 2 the rate of GPs' patients achieving the $2.50 \mathrm{mmol} / \mathrm{L} \mathrm{LDL-C}$ target value is presented; this was $40 \%$ in 2011 , while that of specialists' patients proved to be $45 \%(p=0.137)$. The change in goal achievement rate of GPs between 2010 and 2011 proved to be statistically significant $(p=0.035)$, while that of specialists (39\% in 2010 [18] and 45\% in 2011) was not significant $(p=0.064)$. 
Table I. Characteristics and mean lipid values of the patients of GPs and specialists in the Hungarian MULTI GAP 2011 study

\begin{tabular}{|c|c|c|c|c|}
\hline $\begin{array}{c}\text { Patient } \\
\text { number } \\
(n)\end{array}$ & $\begin{array}{c}\text { Total } \\
\text { cholesterol } \\
{[\mathrm{mmol} / \mathrm{l}]} \\
\text { Mean } \pm \text { SD }\end{array}$ & $\begin{array}{c}\text { LDL } \\
\text { cholesterol } \\
{[\mathrm{mmol} / \mathrm{l}]} \\
\text { Mean } \pm \mathrm{SD})\end{array}$ & $\begin{array}{c}\mathrm{HDL} \\
\text { cholesterol } \\
{[\mathrm{mmol} / \mathrm{l}]} \\
\text { Mean } \pm \mathrm{SD}\end{array}$ & $\begin{array}{c}\text { Triglyceride } \\
{[\mathrm{mmol} / \mathrm{l}]} \\
\text { Mean } \pm \text { SD }\end{array}$ \\
\hline GPs & $5.12 \pm 1.30$ & $2.87 \pm 1.01$ & $1.26 \pm 0.34$ & $1.99 \pm 1.67$ \\
\hline Specialists & $4.97 \pm 1.25$ & $2.77 \pm 1.10$ & $1.29 \pm 0.43$ & $2.05 \pm 1.23$ \\
\hline Gender & & 943 males/683 females & & \\
\hline Age [years] & & $66 \pm 10$ & & \\
\hline BMI (body mass index) & & & $29.0 \pm 10 \mathrm{~kg} / \mathrm{m}^{2}$ & \\
\hline $\begin{aligned} \text { Waist circumference: } & \text { Males }>102 \mathrm{~cm} \\
& \text { Females }>88 \mathrm{~cm}\end{aligned}$ & & $\begin{array}{l}39 \% \\
71 \%\end{array}$ & & \\
\hline eGFR & & $61 \pm 13 \mathrm{ml} / \mathrm{min} / 1.73 \mathrm{~m}^{2}$ & & \\
\hline Smokers & & $27 \%$ & & \\
\hline Unstable angina & & $383(23 \%)$ & & \\
\hline Previous myocardial infarction & & $560(34 \%)$ & & \\
\hline $\begin{array}{l}\text { Known peripheral artery disease: } \\
\text { - (PAD) or vascular operation due to PAD } \\
\text { - Transitory ischemic attack } \\
\text { - Diabetes } \\
\text { - Hypertension }\end{array}$ & & $\begin{array}{l}283(17 \%) \\
279(17 \%) \\
766(46 \%) \\
1430(88 \%)\end{array}$ & & \\
\hline $\begin{array}{l}\text { Lipid lowering therapy (statin, patients' \%,/ } \\
\text { - Simvastatin } \\
\text { - Atorvastatin } \\
\text { - Rosuvastatin } \\
\text { - Fluvastatin } \\
\text { - Ezetimibe } \\
\text { - Fibrates }\end{array}$ & ean daily dose) & $\begin{array}{c}18 \% / 29 \mathrm{mg} \\
46 \% / 32 \mathrm{mg} \\
29 \% / 20 \mathrm{mg} \\
3 \% / 72 \mathrm{mg} \\
16 \% / 10 \mathrm{mg} \\
7 \% / 201 \mathrm{mg}\end{array}$ & & \\
\hline
\end{tabular}

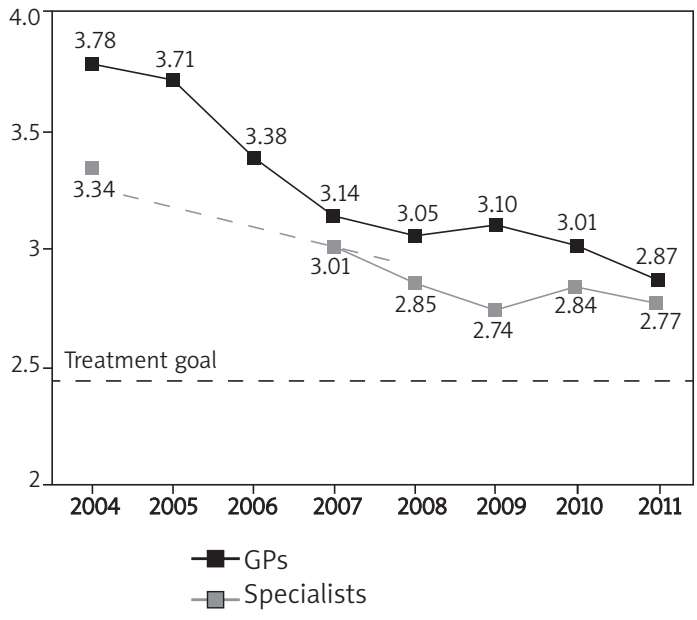

Figure 1. Change in mean LDL-cholesterol levels of high cardiovascular risk patients treated by GPs and specialists, over the years

Among specialists the plan of the physician regarding the treatment of patients whose LDL-cholesterol level was not on goal was evaluated. In $68 \%$ of the cases the physician did not go further, and the patients were left undertreated. In $32 \%$ of the patients with LDL level over $2.50 \mathrm{mmol} / \mathrm{l}$ the following plans were declared for the change of current treatment: in 34\% doubling the dose of statin, in $43 \%$ switching to a stronger statin and in $21 \%$ introduction of combination therapy (in $2 \%$ of cases the plan for therapy modification was not properly declared).

Figure 3 shows the distribution of LDL-C values in the GPs' patients of the MULTI GAP 2011 study. The achievement rate of $2.50 \mathrm{mmol} / \mathrm{LDL}-\mathrm{C}$ was $40 \%$, but that of $1.80 \mathrm{mmol} / \mathrm{l}$ was only $11 \%$.

The 2011 MULTI GAP study also evaluated the patients' compliance with the lipid-lowering medical treatment. This was estimated by the physician based on questioning the patient and the frequency of drug prescriptions. The result was given in percentage. Five groups were formed based on compliance: $60 \%$ or below, $61-70 \%, 71-80 \%, 81-90 \%$ and over $90 \%$ of patients were considered cooperative in each group, respectively. The $2.50 \mathrm{mmol} / \mathrm{LDL}-\mathrm{C}$ target achievement rate was 20\%, 25\%, 28\%, 36\% and $42 \%$, respectively (Figure 4). 


\section{Discussion}

The clinical benefit of lipid-lowering therapy is indisputable and has increasing importance in cardiovascular prevention. According to the new dyslipidemia guidelines of the ESC/EAS $1.80 \mathrm{mmol} / \mathrm{l}$ LDL-cholesterol is recommended for more patients than before [10]. This means that more effort should be made, since even the achievement rate of the $2.50 \mathrm{mmol} / \mathrm{l}$ level could not meet our satisfaction. The medication possibilities are limited (statins and ezetimibe) and in the next few years introduction of a new ground-breaking LDL cholesterol-lowering agent is not expected. Also a few more years must elapse until the promising PCSK9 inhibitor therapy [20] comes into practice. The improvement of lipid parameters beyond LDL-C can happen more frequently with the administration of niacin and fibrates. Also the introduction of CETP inhibitors may occur. These may decrease LDL-C levels as well, but substantial improvement can be expected only from a more effective use of the statin + ezetimibe combination [21].

We have been analyzing the changes in lipid levels and the achievement of the targets in Hungary since 2004 [17, 18]. After the significant fall of lipid levels experienced in the early years, recently stagnation has been observed. We could not be satisfied with attainment of the $2.50 \mathrm{mmol} / \mathrm{LLD}-\mathrm{C}$ level either, and regarding the significantly increased and probably further increasing demands to reach the level of $1.80 \mathrm{mmol} / \mathrm{l}$, we have to look for additional ways to improve.

The Hungarian CORVUS (COntrolled TaRgets for High Vascular Risk Patients Using Effective Statins) study investigated the effect of switching to rosuvastatin on the success of lipid lowering therapy in 1385 high risk patients. In this 3-month, multicenter, prospective, observational, non-interventional, open-label study during the treatment period the level of total cholesterol decreased by $25.2 \%$ and LDL cholesterol by $35.0 \%$; at the end of the study the rate of achieving the $2.50 \mathrm{mmol} / \mathrm{LDL}-\mathrm{C}$ target level was $58 \%$. One thousand and seventy-seven out of 1385 patients belonged to the very high risk category, and in this group of patients the 1.80 $\mathrm{mmol} / \mathrm{L} \mathrm{LDL}-\mathrm{C}$ achievement rate proved to be only $19 \%[22,23]$. This result suggests that statin monotherapy, even in the case of the most potent rosuvastatin, in the majority of very high risk patients is ineffective and the administration of ezetimibe is inevitable.

In the MULTI GAP 2010 study, comparing statin monotherapy vs. combination therapy, a 19\% difference was shown in the $2.50 \mathrm{mmol} / \mathrm{L}$ LDL-cholesterol achievement rate in favour of the latter, i.e. ezetimibe administration [18].

A further tool of achieving better lipid lowering results could be the improvement of therapeutic

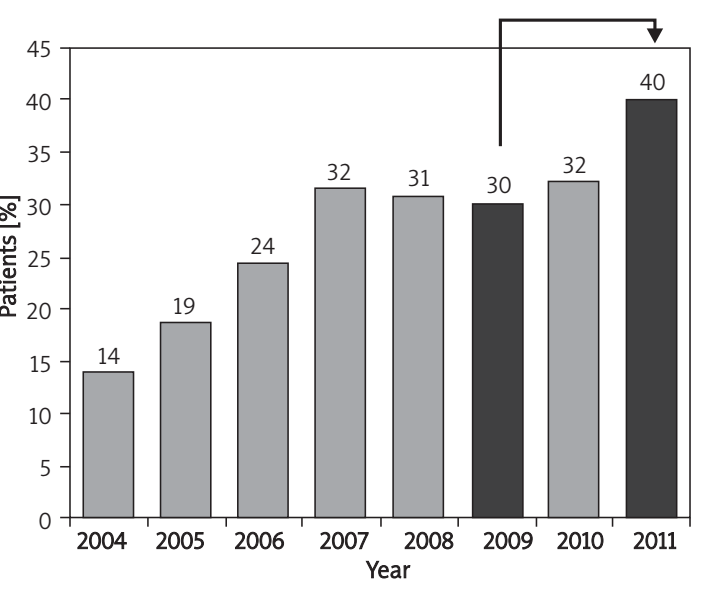

Figure 2. Changes in the ratio of patients reaching the target $2.50 \mathrm{mmol} / \mathrm{l}$ of LDL-cholesterol level treated by GPs between 2004 and 2011

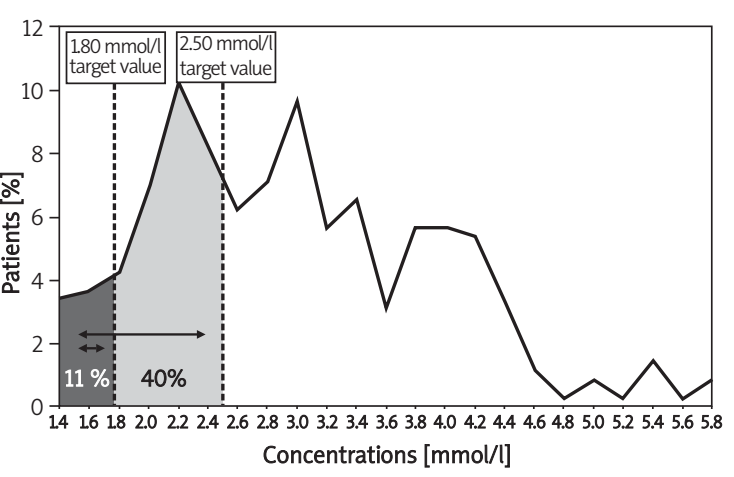

Figure 3. The distribution of LDL-C values in the patients of GPs in the MULTI GAP 2011 study

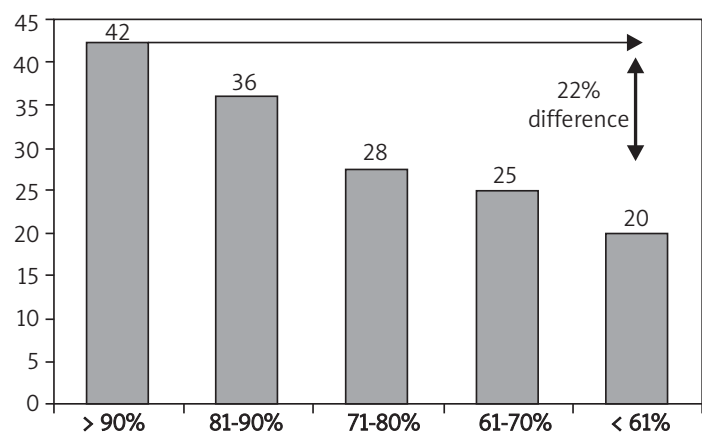

Figure 4. The relationship between the attainment of $2.50 \mathrm{mmol} / \mathrm{I}$ LDL-cholesterol level and the patients' compliance in the MULTI GAP 2011 study

cooperation of the patients. A series of studies has proven a linear correlation between patients' adherence to lipid lowering therapy and long-term survival or rate of clinical events [24-26]. In our 2010 study there was a $17 \%$ difference in target level attainment rate between the good and bad com- 
Table II. Practical guide to reach the 1.80 and 2.50 LDL-cholesterol levels as a function of the starting level

\begin{tabular}{|c|c|c|c|c|c|}
\hline $\begin{array}{l}\text { LDL-C } \\
\text { level [mmol/] } \\
\text { on statin } \\
\text { therapy at the } \\
\text { beginning }\end{array}$ & $\begin{array}{c}\% \text { Reduction } \\
\text { needed }\end{array}$ & $\begin{array}{c}\text { Practical approach } \\
\text { to reach target } \\
1.80 \mathrm{mmol} / \mathrm{l} \mathrm{LDL-C} \\
\text { in very high risk } \\
\text { patients }\end{array}$ & $\begin{array}{l}\text { LDL-C } \\
\text { level [mmol/] } \\
\text { on statin } \\
\text { therapy at the } \\
\text { beginning }\end{array}$ & $\begin{array}{c}\% \text { Reduction } \\
\text { needed }\end{array}$ & $\begin{array}{l}\text { Practical approach } \\
\text { to reach target } \\
2.50 \mathrm{mmol} / \mathrm{l} \text { LDL-C } \\
\text { high risk } \\
\text { patients }\end{array}$ \\
\hline 2.0 & $10 \%$ & Double the statin dose & 2.0 & & \multirow{3}{*}{$\begin{array}{l}\text { No therapy modification } \\
\text { needed, regular check } \\
\text { of LDL-C level }\end{array}$} \\
\hline 2.2 & $18 \%$ & \multirow{2}{*}{$\begin{array}{c}\text { Switch to a more } \\
\text { potent statin }\end{array}$} & 2.2 & & \\
\hline 2.4 & $25 \%$ & & 2.4 & & \\
\hline 2.6 & $31 \%$ & \multirow{9}{*}{$\begin{array}{l}\text { Consideration of } \\
\text { combination therapy } \\
\text { according to the guide- } \\
\text { lines (ezetimibe/fibrate/ } \\
\text { nicotinic acid and statin) }\end{array}$} & 2.6 & $4 \%$ & Double the statin dose \\
\hline 2.8 & $36 \%$ & & 2.8 & $11 \%$ & \multirow{2}{*}{$\begin{array}{l}\text { Switch to a more } \\
\text { potent statin }\end{array}$} \\
\hline 3.0 & $40 \%$ & & 3.0 & $17 \%$ & \\
\hline 3.2 & $44 \%$ & & 3.2 & $22 \%$ & \multirow{6}{*}{$\begin{array}{l}\text { Consideration of } \\
\text { combination therapy } \\
\text { according to the } \\
\text { guidelines } \\
\text { (ezetimibe/fibrate/nicotinic } \\
\text { acid and statin) }\end{array}$} \\
\hline 3.4 & $47 \%$ & & 3.4 & $26 \%$ & \\
\hline 3.6 & $50 \%$ & & 3.6 & $31 \%$ & \\
\hline 3.8 & $53 \%$ & & 3.8 & $34 \%$ & \\
\hline 4.0 & $55 \%$ & & 4.0 & $38 \%$ & \\
\hline$>4.2$ & $57 \%$ & & $>4.2$ & $40 \%$ & \\
\hline
\end{tabular}

pliance group [18]. The MULTI GAP 2011 study proved again the linear correlation between the patients' cooperation in drug taking and achievement of the LDL-C target value (Figure 4); there was not a statistically significant difference compared with the results of 2010 .

The patients' willingness to cooperate is crucial. In a recent study, according to the database of the Hungarian National Health Insurance Fund, the dispensation rate of prescribed statins in patients' newly placed on statin therapy was analyzed and it showed that in the second and third months of the treatment about half of the patients did not go to the pharmacy for the prescribed drugs and a year later this proportion became only $26.3 \%$ [27]. The most obvious possibility for improvement is that at every drug prescription the patient's attention should be drawn to the long-term commitment as the treatment needs appropriate cooperation in order to maximize the benefits and reduce the frequency of clinical events.

In the MULTI GAP 2010 study the physicians receiving special education and access to software which called attention to the patients' weaknesses in achieving their lipid goals had $10-11 \%$ better results in reaching the $2.5 \mathrm{mmol} / \mathrm{LLD}-\mathrm{C}$ target level than doctors without the special education [18]. This supports the ideas of further education and use of computer software application which facilitates their work while both enhance target achievement rates. According to the MULTI GAP 2011 survey 68\% of the physicians do not modify the therapy when the patients' lipid results do not meet the targets. This high number confirms the fact that the con- tinuing education of physicians is essential. For this Table II may serve as guidance showing which therapeutic options (dose doubling, switching to a stronger statin or combination with ezetimibe) to choose depending on the appropriate target value $(2.50 \mathrm{mmol} /$ lor $1.80 \mathrm{mmol} / \mathrm{l})$ and the current LDL-C level. Experience shows that physicians need and are willing to receive help from such materials.

In conclusion, we can summarize that target level achievements indicating the quality of treatment in lipid-lowering therapy have significantly improved in recent years; however, the momentum of improvement came to a halt. To achieve further improvements possibilities are available both at the patients' and doctors' sides. On one side, continuous monitoring of patients' co-operation is needed to improve their adherence. The physician should inform the patient that the lipid-lowering therapy is a lifelong activity which, if successful, could stop the process of atherosclerosis and regression can be achieved. On the other side, at every doctorpatient meeting the importance of management should be emphasized and after each laboratory control the previous treatment should be reviewed. This belongs to the improvement of medical activity. The key to improving the quality of lipid-lowering is based on the doctor's knowledge and his/her attitude to the lipid-lowering therapy and these can be assisted by MULTI GAP or other similar surveys.

\section{Acknowledgments}

The various studies analyzed in this paper were conducted by Dendrite Ltd, Hungary. All authors had full access to all the data in the study, take 
responsibility for the integrity of the data and the accuracy of the data analyses, and agreed to the manuscript as written. The authors have given talks, attended conferences and participated in other trials or advisory boards sponsored by various pharmaceutical companies. This material was written independently, and no company or institution supported the authors financially. No professional writer was involved.

\section{References}

1. Baigent C, Blackwell L, Emberson J, et al. Cholesterol Treatment Trialists' CTT Collaboration. Efficacy and safety of more intensive lowering of LDL cholesterol: a metaanalysis of data from $170 ? 000$ participants in 26 randomised trials. Lancet 2010; 376: 1670-81.

2. Robinson JG, Wang S, Smith BJ, Jacobson TA. Metaanalysis of the relationship between non-high-density lipoprotein cholesterol reduction and coronary heart disease risk. J Am Coll Cardiol 2009; 53: 316-22.

3. Chan DKY, O'Rourke F, Shen Q, Mark JCS, Hung WT. Meta-analysis of the cardiovascular benefits of intensive lipid lowering with statins. Acta Neurol Scand 2011; 124: 188-95.

4. Sattar N, Preiss D, Murray HM, et al. Statins and risk of incident diabetes: a collaborative meta-analysis of randomised statin trials. Lancet 2010; 375: 735-42.

5. Preiss D, Seshasai SR, Welsh P, et al. Risk of incident diabetes with intensive-dose compared with moderatedose statin therapy: a meta-analysis. JAMA 2011; 305: 2556-64.

6. Hennekens $\mathrm{CH}$, Drowos J. Statins: the high risks of discontinuation and large benefits of continuation. Arch Med Sci 2011; 7: 931-2.

7. Nissen SE, Tuczcu M, Schoenhagen P, et al. Effect of intensive compared with moderate lipid-lowering therapy on progression of coronary atherosclerosis. A randomized controlled trial. JAMA 2004; 291: 1071-80.

8. Nissen SE, Nicholls SJ, Sipahi I, et al. Effect of very highintensity statin therapy on regression of coronary atherosclerosis. The ASTEROID Trial. JAMA 2006; 295: 1556-65.

9. Nicholls SJ, Ballantyne CM, Barter PJ, et al. Effect of two intensive statin regimens on progression of coronary disease. N Engl J Med 2011; 365: 2078-87.

10. Reiner Z, Catapano AL, De Backer G et al. The Task Force for the management of dyslipidaemias of the European Society of Cardiology (ESC) and the European Atherosclerosis Society (EAS). ESC/EAS Guidelines for the management of dyslipidaemias. Eur Heart J 2011; 32: 1769-818.

11. Kotseva K, Wood D, De Backer G, De Bacquer D, Pyörälä K, Keil U; EUROASPIRE Study Group. Cardiovascular prevention guidelines in daily practice: a comparison of EUROASPIRE I, II, and III surveys in eight European countries. Lancet 2009; 373: 929-40.

12. Hermans MP, Cabezas MC, Strandberg T, et al. Centralized Pan-European survey on the under-treatment of hypercholesterolaemia (CEPHEUS): overall findings from eight countries. Curr Med Res Opin 2010; 26: 445-54.

13. Katsiki N, Mikhailidis DP, Athyros VG, et al. Are we getting to lipid targets in real life? Arch Med Sci 2010; 6: 639-41.

14. Packard CJ. Benefits of lipid regulation in acute coronary syndrome. Arch Med Sci 2010; 6 (Suppl 1A): S76-S82.

15. Leiter LA, Lundman P, da Silva PM, et al. DYSIS investigators. Persistent lipid abnormalities in statin- treated patients with diabetes mellitus in Europe and Canada: results of the Dyslipidaemia International Study. Diabet Med 2011; 28: 1343-51.

16. Karalis DG, Subramanya RD, Hessen SE, Liu L, Victor MF. Achieving optimal lipid goals in patients with coronary artery disease. Am J Cardiol 2011; 107: 886-90.

17. Mark L, Paragh G, Karadi I, Reiber I, Pados G. Changes in attainment of lipid goals by general practitioners and specialists in patients at high cardiovascular risk in Hungary during 2004-2008. Arch Med Sci 2010; 6: 695-700.

18. Mark L, Paragh G, Karadi I, Reiber I, Pados G, Kiss Z. An attempt to make lipid-lowering therapy more effective in Hungary. The results of MULTI GAP 2010 and the Plus Program. Arch Med Sci 2011; 7: 760-6.

19. The IV. Hungarian Cardiovascular Consensus Conference. Metabolizmus 2010; 8 Suppl A: 2-96.

20. Akram ON, Bernier A, Petrides F, et al. Beyond LDL cholesterol, a new role for PCSK9. Arterioscler Thromb Vasc Biol 2010; 30: 1279-81.

21. Pandey S, Bissonnette S, Boukas S, et al. Effectiveness and tolerability of ezetimibe co-administered with statins versus statin dose-doubling in high-risk patients with persistent hyperlipidemia: The EZE(STAT)2 trial. Arch Med Sci 2011; 7: 767-75.

22. Mark L, Paragh G, Reiber I. The role of ezetimibe in LDL cholesterol goal attainment in very high risk patients. The rosuvastatin monotherapy looks to be insufficient. Curr Med Res Opin 2011; 27: 1959-60.

23. Mark L, Reiber I, Bajnok L, Karadi I, Paragh G. The Effect of Switching to the High-Efficient Rosuvastatin on the Success of Lipid Lowering Therapy in High Risk Patients. The CORVUS (Controlled Targets for High Vascular Risk Patients Using Effective Statins) Study. Pharm Anal Acta 2012; S10: 001. doi:10.4172/2153-2435.S10-001.

24. Gitt AK, Drexel H, Feely J, et al. Persistent lipid abnormalities in statin-treated patients and predictors of LDL-cholesterol goal achievement in clinical practice in Europe and Canada. Eur J Cardiovasc Prev Rehabil 2012; 19: 221-30.

25. Simpson SH, Eurich DT, Majumdar SR, et al. A metaanalysis of the association between adherence to drug therapy and mortality. BMJ 2006; 333: 15.

26. Rasmussen JN, Chong A, Alter DA. Relationship between adherence to evidence-based pharmacotherapy and long-term mortality after acute myocardial infarction. JAMA 2007; 297: 177-186.

27. Jermendy G, Wittmann I, Nagy L, et al. Persistence of oral antidiabetic treatment among patients with type 2 diabetes in Hungary, 2007-2008. Metabolizmus 2011; 9: 21-7. 